\title{
Flexibility and fatigue evaluation of oblique as compared with anterior lumbar interbody cages with integrated endplate fixation
}

\author{
Andrew L. Freeman, MS, ${ }^{1}$ William J. Camisa, MS, ${ }^{1}$ Glenn R. Buttermann, MD, ${ }^{2}$ and \\ James R. Malcolm, MD³ \\ ${ }^{1}$ Excelen Center for Bone and Joint Research, Minneapolis, Minnesota; ${ }^{2}$ Midwest Spine Institute, Stillwater, Minnesota; and \\ ${ }^{3}$ Pinnacle Orthopaedics, Marietta, Georgia
}

\begin{abstract}
OBJECTIVE This study was undertaken to quantify the in vitro range of motion (ROM) of oblique as compared with anterior lumbar interbody devices, pullout resistance, and subsidence in fatigue.

METHODS Anterior and oblique cages with integrated plate fixation (IPF) were tested using lumbar motion segments. Flexibility tests were conducted on the intact segments, cage, cage + IPF, and cage + IPF + pedicle screws (6 anterior, 7 oblique). Pullout tests were then performed on the cage + IPF. Fatigue testing was conducted on the cage + IPF specimens for 30,000 cycles.
\end{abstract}

RESULTS No ROM differences were observed in any test group between anterior and oblique cage constructs. The greatest reduction in ROM was with supplemental pedicle screw fixation. Peak pullout forces were $637 \pm 192 \mathrm{~N}$ and 651 $\pm 127 \mathrm{~N}$ for the anterior and oblique implants, respectively. The median cage subsidence was $0.8 \mathrm{~mm}$ and $1.4 \mathrm{~mm}$ for the anterior and oblique cages, respectively.

CONCLUSIONS Anterior and oblique cages similarly reduced ROM in flexibility testing, and the integrated fixation prevented device displacement. Subsidence was minimal during fatigue testing, most of which occurred in the first 2500 cycles.

http://thejns.org/doi/abs/10.3171/2015.4.SPINE14948

KEY WORDS fatigue; interbody cage; interbody device; lumbar spine biomechanics; pullout testing; subsidence

I UMBAR spinal fusion may be achieved using anterior or posterior devices to stabilize the spine during the bone fusion period. Posterior lumbar surgery has been shown to adversely affect the paraspinal muscles., ${ }^{512-14,19,21,22,24}$ Anterior interbody techniques that use structural bone graft or cage devices have the advantage of reliably increasing disc height with indirect foraminal decompression, restoring lordosis, and avoiding epidural scarring and radiculitis related to posterior interbody techniques. ${ }^{11,15}$

"Standalone" interbody fusion devices are appealing because they avoid supplemental posterior fixation and spinal muscle injury related to the fusion. These devices may also reduce implant costs related to the posterior procedure and operative time. Standalone fusion devices require adequate fixation to the anterior vertebral column, either by supplemental plates or screws or by integrated fixation intended to prevent device dislodgment and enhance motion segment rigidity. Devices with integrated fixation typically have a lower profile and require less exposure to implant as compared with cages supplemented with independent plates. Furthermore, cages with integrated plates require less exposure than cages with integrated bone screws, which necessitate high-angle trajectories for insertion.

One challenge of interbody device implantation is device design: most are designed for a direct anterior approach, which may be difficult at L4-5 due to the vascular anatomy, thereby increasing surgical risk., ${ }^{3,26}$ Furthermore, standalone anterior interbody devices with multipoint screw fixation require greater exposure, which again may be difficult at L4-5. To overcome this concern, oblique and extreme lateral interbody fusion devices have been developed that are placed by an anterolateral or transpsoas lat-

ABBREVIATIONS DEXA = dual-energy $x$-ray absorptiometry; IPF = integrated plate fixation; ROM = range of motion.

SUBMITTED October 24, 2014. ACCEPTED April 10, 2015.

INCLUDE WHEN CITING Published online September 25, 2015; 10.3171/2015.4.SPINE14948. 
eral approach, respectively. Thus, a cage that has the same biomechanical support as an anterior device but is safer to implant would be preferable to use clinically. Yet another concern is the lack of dynamic performance data for cages. Although prior flexibility studies suggest that the ability of standalone devices to produce a rigid motion segment is sufficient, ${ }^{1,4,6}$ the construct rigidity of standalone devices over time in vivo is not well understood.

The purposes of this study were to determine whether an anterolateral oblique interbody cage would perform as well as a conventional anteriorly placed device and to assess the effects of supplemental fixation. Additionally, because flexibility testing may represent only the immediate postoperative period, cyclic loading (30,000 cycles) was performed to assess device subsidence in the early in vivo state.

\section{Methods \\ Specimen Preparation}

Fourteen L1-S1 cadaver lumbar spine specimens (cadaver age range 40-67 years, 9 men and 5 women) were scanned using dual-energy x-ray absorptiometry (DEXA; GE Lunar, iDXA) to quantify bone density. The specimens were dissected, preserving all ligamentous structures, into a total of 26 L2-3 and L4-5 motion segments. The motion segments were divided into a flexibility and pullout testing group and a fatigue testing group, with 6 anterior and 7 oblique devices in each group. Specimens were potted as previously described. ${ }^{1}$

For both the anterior and oblique interbody cages, flexibility testing was performed on the following configurations: 1) intact spinal motion segments; 2) isolated cage; 3 ) cage + integrated plate fixation (IPF); and 4) cage + IPF + pedicle screws and rods (Fig. 1). Following the intact tests, discectomies were performed by an experienced spine surgeon (G.R.B. and J.R.M.). For the anterior implants, the midline was identified and an annulotomy was performed laterally for $1.5-2 \mathrm{~cm}$ bilaterally. For the oblique implant, the midline was identified and the annulotomy was made to the left of midline for approximately $3.5 \mathrm{~cm}$. Complete cleaning of the disc space was performed to accommodate the cages. The cages were sized using trial instruments to slightly distract the disc space and to provide a snug fit for the device. Correctly sized anterior (ROI-A, LDR Spine; footprint size: 5 cages measuring $27 \times 36 \mathrm{~mm}$ and 1 cage measuring $30 \times 39 \mathrm{~mm}$ ) or oblique polyetheretherketone (PEEK) cages (ROI-A Oblique, LDR Spine; footprint size: 4 cages measuring $27 \times 30 \mathrm{~mm}$ and 3 measuring $30 \times 33$ $\mathrm{mm}$ ) were inserted into each specimen. Flexibility tests were conducted after cage implantation. Two integrated fixation plates were then deployed and flexibility testing was repeated. Final flexibility tests were conducted after supplementation with pedicle screws. Fluoroscopic images were acquired for each instrumented condition to confirm implant position and sizing.

\section{Flexibility Testing}

Flexibility tests were conducted by applying pure moments of $\pm 6 \mathrm{Nm}$ at $0.5 \mathrm{Nm} / \mathrm{sec}$ with a $50-\mathrm{N}$ compressive preload to the superior vertebral body using a hydraulically actuated spinal loading fixture (MTS 858 Mini
Bionix, MTS Systems). ${ }^{6}$ The inferior vertebral body was mounted to a passive XY slide table, and a load cell with 6 degrees of freedom mounted directly above the specimen was used to control the application of loads and moments. Data were collected only on the third cycle. A noncontact motion measurement system was used to track 3D spinal motion, as described previously., ${ }^{9,10,25}$ Range of motion (ROM) was calculated as the difference between the peak positive and peak negative rotations, while neutral zone was calculated as the amount of motion in the low-load region, between $-0.25 \mathrm{Nm}$ and $+0.25 \mathrm{Nm}$.

\section{Pullout Testing}

After flexibility testing was completed, the pedicle screws and rods were removed from each specimen, and pullout testing was performed on the cages with fixation plates. An aluminum block was directly screwed to the exposed face of the cage and connected to the machine actuator with a swaged steel cable (Fig. 2). The implant was pulled out of the motion segment in a direction perpendicular to the face of the device. A 400-N axial compressive force was applied during pullout using a fixture previously described. ${ }^{1}$ Pullout tests were conducted at 10 $\mathrm{mm} / \mathrm{min}$ with data acquisition at $20 \mathrm{~Hz}$. The peak pullout load was calculated as the maximum load sustained by the device. The mechanism of failure (i.e., device or vertebral body failure) was recorded for each pullout test.

\section{Fatigue Testing}

Motion segments implanted with either anterior or oblique interbody cages with IPF were wrapped in salinesoaked gauze and tested in flexion-extension and lateral bending by applying pure moments of $\pm 5 \mathrm{Nm}$ at $1 \mathrm{~Hz}$ with a $400 \mathrm{~N}$ follower load (Fig. 3). A custom-designed pneumatic follower load system was used to apply a 200$\mathrm{N}$ load to each side of the spine for a cumulative load of $400 \mathrm{~N}$. Load cells were placed in-line with the follower load cables to continuously monitor the applied load. The follower load cables were placed at the approximate center of the vertebral bodies in the sagittal plane and adjusted such that follower load-induced rotations were less than $0.25^{\circ}$. Fatigue testing was alternated between 2500 cycles of flexion-extension and 2500 cycles of lateral bending until 30,000 cumulative cycles were performed.

Implant subsidence was quantified by lateral fluoroscopy (OEC $9900 \mathrm{C}$-arm, GE Healthcare) at 10, 100, 1000, and 2500 cycles and at each 2500-cycle increment thereafter. Specimens were carefully positioned on a rigid table by placing the potting material against physical "stops" with index lines for specimen alignment. The mobile fluoroscopy unit was not disturbed following the initial setup of lateral and anteroposterior images of the specimen, and all images were acquired and saved using the detached monitor and control unit. The techniques used for fluoroscopic image acquisition resulted in nearly perfect image overlays for each cyclic time point and allowed for accurate disc height measurements. Disc height measurements were performed in Adobe Illustrator. Images were placed into individual layers for each cyclic time point, magnified by approximately $1200 \%$ to allow precise visualiza- 

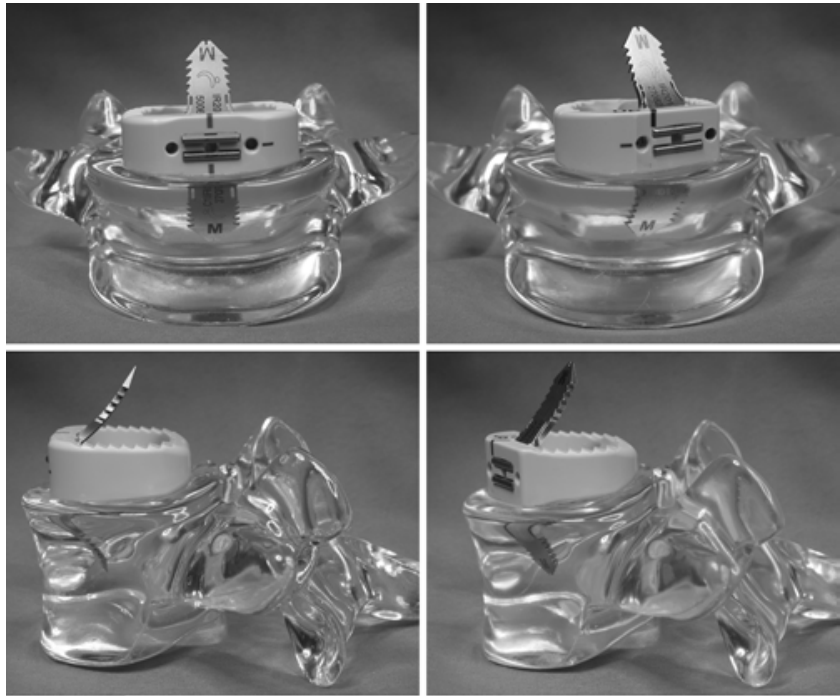

Anterior Cage

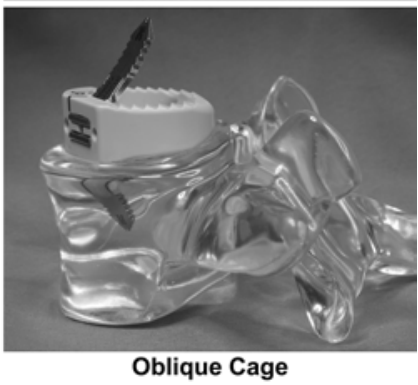

FIG. 1. The anterior (left) and oblique (right) interbody cages with anchor plates.

tion of the endplate/disc interface, and vertical lines were measured at the middle of the disc to quantify disc height. A machined 20-mm reference was placed in each fluoroscopic image for proper scaling. At the completion of fatigue testing, each specimen was disarticulated to perform a visual and photographic examination of the vertebral body endplates and failure mode.

\section{Statistical Analysis}

A 1-way repeated-measures ANOVA was performed to examine statistical differences in ROM data for each test direction. Nonnormal ROM data were analyzed using a repeated-measures ANOVA on ranks. A t-test was performed to examine statistical differences in flexionextension and axial torsion ROM between the oblique cage + IPF and the anterior cage + IPF. Due to unequal variances, a rank-sum test was performed on the lateral bending ROM data for the oblique versus anterior device comparison. Linear regression was used to evaluate the relationship between pullout load and bone mineral density. A t-test was performed on the subsidence data at 30,000 cycles to analyze differences between the 2 test groups. Statistical significance was declared at $\mathrm{p}<0.05$.

\section{Results}

\section{Flexibility Testing}

The average $( \pm$ SD) DEXA T-scores were $-0.1 \pm 1.2$, and the difference between the anterior and oblique groups was not significant $(p=0.64)$. The ROM of the intact motion segments was similar for the anterior and oblique groups (Table 1). Implantation of the isolated oblique cage reduce ROM by $33 \%$ in flexion-extension and $27 \%$ in lateral bending, but differences from intact motion segments were not significant. In axial torsion, the isolated oblique cage resulted in an average increase in ROM of $84 \%$ due to excision of the annulus for device placement. Implantation of the anterior interbody cage significantly reduced motion in flexion-extension by $42 \%$ and in lateral bending

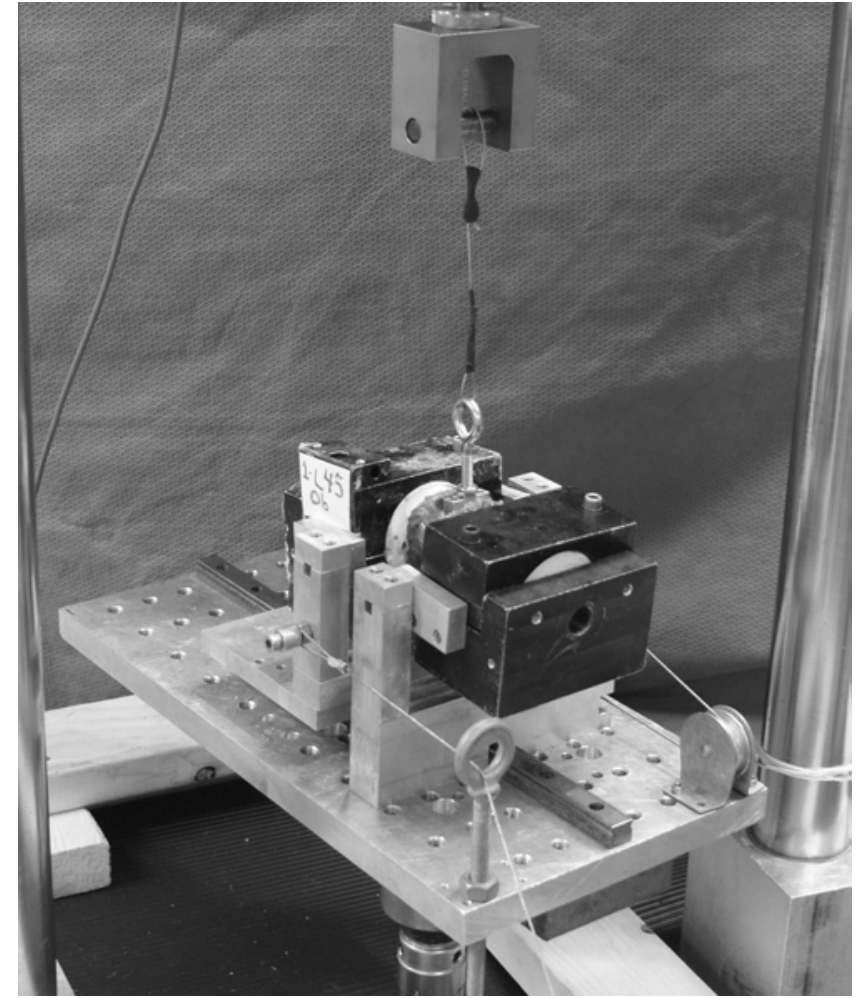

FIG. 2. The interbody spacers were pulled out of each motion segment in a direction perpendicular to the exposed face of the device (anterior or oblique). A 400-N compressive load was applied to the motion segment during pullout testing using a system of cables, pulleys, and dead weights.

by $61 \%$ ( $\mathrm{p} \leq 0.02$ vs intact). The anterior interbody cage increased ROM in axial torsion by $19 \%$. There were no significant differences between the anterior and oblique cages in flexion-extension, lateral bending, or torsion.

Both the anterior and oblique cage groups experienced little difference in ROM when the IPFs were deployed. The IPFs were most effective in torsion, where ROM was reduced by $1.8^{\circ}$ with IPF deployment as compared with the oblique isolated cage, and by $1.5^{\circ}$ for the anterior cage.

Pedicle screws and rods were the most effective at reducing ROM in both the anterior and oblique groups, with overall reductions from intact ROM of $85 \% \pm 10 \%$ in flexion-extension, $88 \% \pm 7 \%$ in lateral bending, and $63 \%$ $\pm 23 \%$ in axial torsion. There was no significant difference in ROM between cage types with the addition of supplemental fixation.

\section{Pullout Testing}

The peak pullout loads were similar between the two groups, with an average of $651 \pm 127 \mathrm{~N}$ for the oblique group and $637 \pm 192 \mathrm{~N}$ for the anterior group. There was no relationship between bone mineral density and pullout load for either group. The failure mechanism for all specimens was anterior (anterior group) or anterolateral (oblique group) vertebral body fracture resulting from pulling the plates through the bone. No cage fractures occurred. 


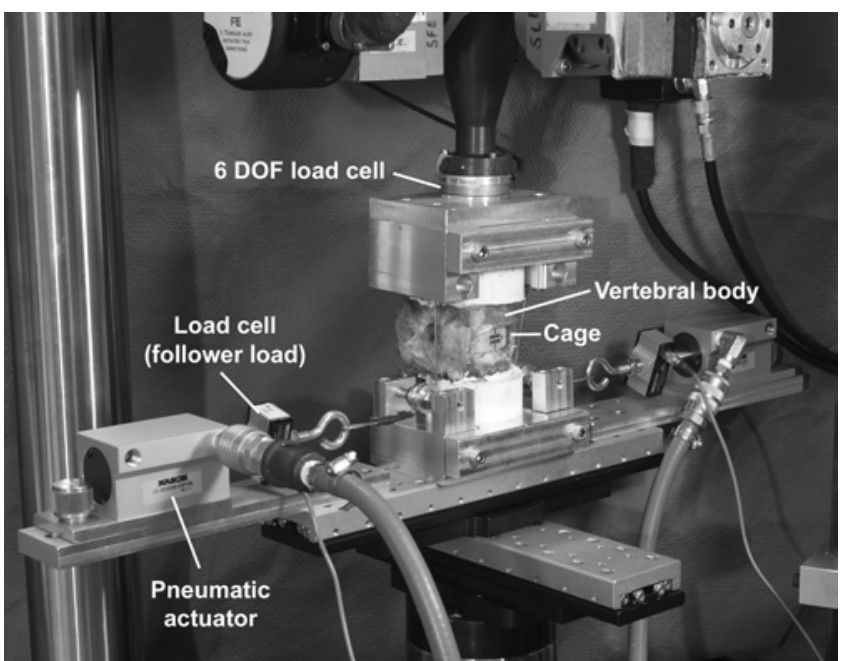

FIG. 3. Fatigue testing was conducted using a follower load system consisting of bilateral pneumatic actuators that applied a constant 200-N load to the cables. Load cells were positioned in line with the cables to monitor the applied loads. DOF = degrees of freedom.

\section{Fatigue Testing}

All specimens successfully completed fatigue testing without any damage to the interbody cage. No instances of vertebral body fractures were noted, and on average, the devices experienced very little anterior migration as measured from the posterior implant marker $(<1 \mathrm{~mm})$. After 30,000 cycles of loading, no significant differences in subsidence were noted between the anterior and oblique implants, with median values of $0.8 \mathrm{~mm}$ and $1.4 \mathrm{~mm}$, respectively ( $p=0.096$; Fig. 4). The oblique group had two outliers, with 3-5 mm of subsidence noted in spacers with below-average footprint size. For both groups, most implant displacement occurred during the first 2500 cycles, with a median subsidence of $0.4 \mathrm{~mm}$ for the anterior group and $1.0 \mathrm{~mm}$ for the oblique group.

\section{Discussion}

The present study provides a comprehensive biomechanical characterization of both oblique and anterior cages with IPF, in terms of flexibility, pullout resistance, and fatigue loading subsidence. While flexibility and pullout testing are commonly performed on interbody spacers with integrated fixation, this study also conducted fatigue testing at physiological loads.

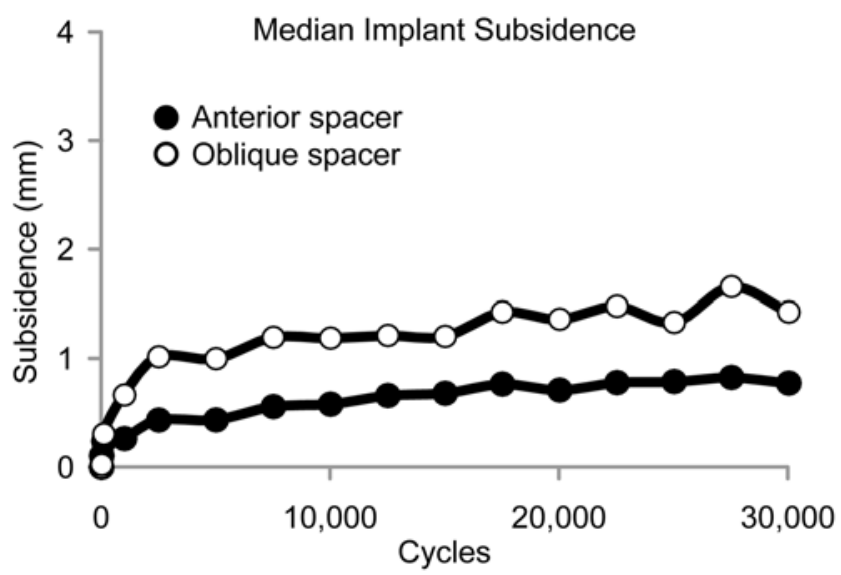

FIG. 4. Graph of the median subsidence of the anterior and oblique cages + IPF as measured from fluoroscopic images. All interbody height changes were due to bone endplate subsidence, and no cage failures were observed.

Specifically, the study demonstrated that an interbody spacer reduced ROM in bending and, with integrated fixation plates, also reduced ROM in torsion; thus, the devices impart increased rigidity to the motion segment. The greatest reduction in $\mathrm{ROM}$ in all axes of rotation resulted from the addition of pedicle screw fixation. The degree of motion reduction for the devices of this study is essentially identical to what has been previously reported for interbody cages with and without supplemental fixation (Fig. 5). 1,4,6 As previously shown, anterior supplemental instrumentation decreased torsion ROM. The present study also found that a cage that is designed to be inserted obliquely (using the anterolateral approach) rather than by direct anterior insertion gives the same degree of rigidity. The cages used in this study, with their integrated fixation plates, were able to resist migration; the pullout test results were similar to a previous study of a device with multiple bone screws. ${ }^{1}$

Flexibility testing has limitations and it has been recommended that cyclic or fatigue testing may better mimic the in vivo state. Subsidence of interbody devices by 1-4 $\mathrm{mm}$ is common and has been previously described. . $^{5,23}$ Clinically, fusion may still occur despite mild subsidence if the biological environment is sufficiently healthy. However, in some instances, subsidence can lead to instability and secondary pseudarthrosis.,17,20 Assuming that fatigue testing may be a better predictor of in vivo performance during the early fusion period, this test was

TABLE 1. Average ROM for the anterior and oblique interbody cages*

\begin{tabular}{|c|c|c|c|c|c|c|c|c|}
\hline \multirow[b]{2}{*}{ Direction } & \multicolumn{2}{|c|}{ Intact } & \multicolumn{2}{|c|}{ Isolated Cage } & \multicolumn{2}{|c|}{ Cage + IPF } & \multicolumn{2}{|c|}{$\begin{array}{c}\text { Cage }+ \text { IPF }+ \text { Pedicle } \\
\text { Screws }\end{array}$} \\
\hline & Anterior & Oblique & Anterior & Oblique & Anterior & Oblique & Anterior & Oblique \\
\hline Flexion-extension $\left({ }^{\circ}\right)$ & $10.1 \pm 4.7$ & $8.8 \pm 1.9$ & $5.9 \pm 3.7 \dagger \ddagger$ & $5.9 \pm 3.4$ & $5.9 \pm 4.3 \dagger \ddagger$ & $6.5 \pm 3.9 \dagger$ & $1.2 \pm 0.5 \ddagger$ & $1.4 \pm 0.9 \ddagger$ \\
\hline Lateral bending $\left(^{\circ}\right)$ & $9.4 \pm 2.0$ & $8.8 \pm 2.5$ & $3.7 \pm 1.5 \dagger \ddagger$ & $6.4 \pm 4.0 \dagger$ & $3.1 \pm 1.3 \dagger \ddagger$ & $5.7 \pm 3.1 \uparrow$ & $0.9 \pm 0.4 \ddagger$ & $1.2 \pm 0.5 \ddagger$ \\
\hline Axial torsion $\left({ }^{\circ}\right)$ & $3.6 \pm 2.1$ & $3.2 \pm 3.7$ & $3.9 \pm 2.2 \dagger$ & $5.3 \pm 5.4 \dagger$ & $2.5 \pm 1.7 \dagger$ & $3.5 \pm 3.2$ & $0.9 \pm 0.5 \ddagger$ & $1.0 \pm 0.5$ \\
\hline
\end{tabular}

* All data given as means \pm SDs.

$\dagger p<0.05$ versus pedicle screws.

$\ddagger p<0.05$ versus intact screws. 

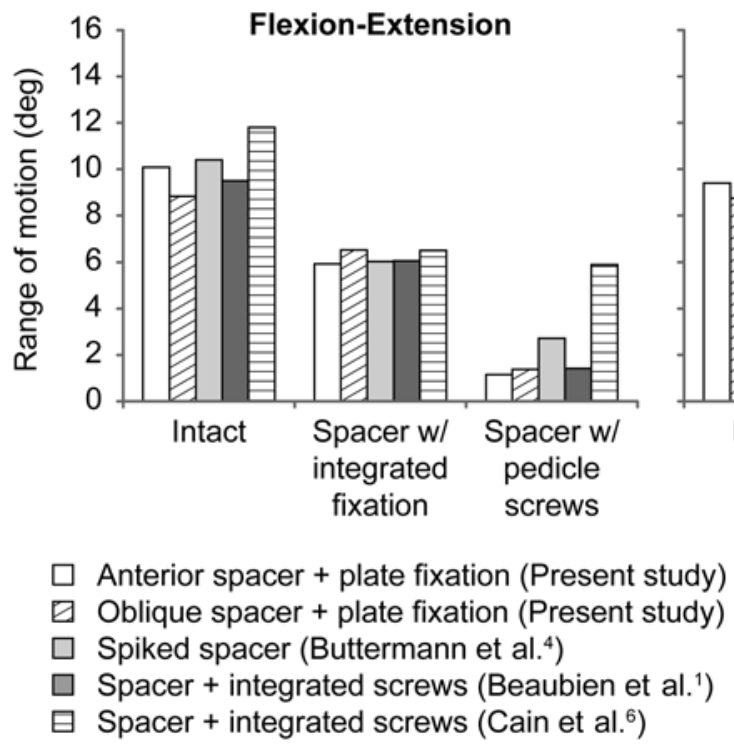

Axial Torsion
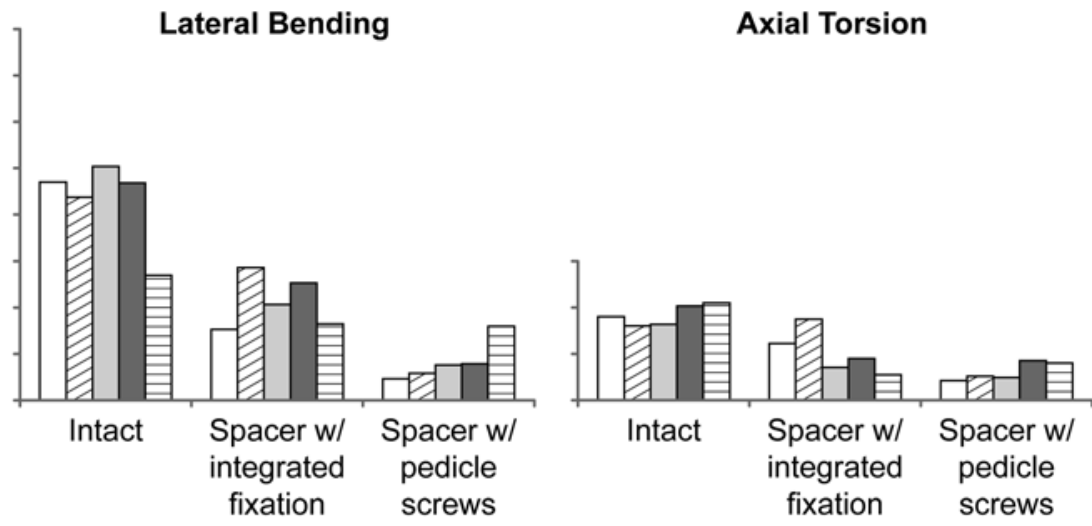

FIG. 5. Range of motion data for the anterior and oblique interbody cages with integrated fixation plates in comparison with similar anterior lumbar interbody fusion cages with integrated fixation.

included in the present study, which found subsidence to occur typically within the first 2500 cycles. We expected, but were unable to find, a relationship between subsidence and DEXA score, probably due to the small number of specimens used in this study. Although not statistically significant, subsidence was greater in the cases in which the oblique spacer was used relative to the anterior device. The testing protocol for this study required that the annulotomy window for implantation of the oblique spacer not pass the midsagittal plane. Because of this smaller annular window, typically smaller interbody spacers were used. This meant that spacers had a smaller "footprint" for the oblique case, and often these interbody devices were placed more centrally rather than having peripheral endplate support, which is related to endplate fracture and subsidence. ${ }^{16,18}$

Although this study exhibited a number of strengthsincluding the use of a well-standardized flexibility test protocol that allowed direct comparison with prior studies, and unique fatigue loading to simulate early in vivo performance-the study also demonstrated some weaknesses. Limitations included the inherent variability found in cadaveric specimens, among which are variation in size, bone quality, and endplate thickness and strength, which could affect subsidence and fixation of the integrated plates. Microfracture, which was not apparent during the implantation, was found to occur in 2 oblique specimens, which skewed the results for the oblique case. Although the overall sample size was large (26 motion segments), a post hoc power analysis indicated that the sample size would need to be more than doubled (60 motion segments) to provide adequate statistical power. Due to both testing time and funding constraints a larger sample size could not be used. Another limitation is that selected implant size was left to surgeon preference at the time of implantation, rather than being based on a strict criterion whereby a specific cage required a predetermined area of coverage for a given endplate size; this variable may have affected stability. Despite cyclic testing, it remains possible that, clinically, patients may have greater subsidence than we found in the present study for the standalone condition. On the other hand, fatigue loading was not performed with supplemental pedicle screw fixation, as may be used clinically, and so the subsidence found in this study may also be considered a worst case.

Clinically, the current study suggests that the interbody cage tested, with its integrated fixation plates, gives the surgeon the option of implanting such a device through a more limited exposure while retaining the same ability as other devices to enhance rigidity required for fusion and avoid cage migration or displacement. Particularly at L4-5, where exposure may be difficult, the oblique spacer may have a clinical advantage yet perform similarly to its anterior counterpart and other devices currently available for this type of procedure. A lumbar interbody device that requires less exposure offers the secondary benefit of minimizing scar tissue at adjacent levels, which is relevant should the adjacent levels ever require future treatment.

\section{Conclusions}

Lumbar interbody cages with integrated fixation to the vertebral endplates reliably enhance motion segment rigidity, and oblique interbody devices are as effective as anteriorly placed devices. Rigidity was greatest with the use of supplemental posterior fixation. Pullout testing required greater than $600 \mathrm{~N}$ and required vertebral body fracture for failure; therefore, anterior displacement of these types of devices is an unlikely mode of clinical failure. Subsidence of 1-3 mm with 30,000-cycle compressive and bending fatigue loading was insignificantly greater for the oblique spacer, which had a smaller footprint. The correlation between subsidence, implant stability, fusion rate, and clinical outcomes requires further study. 


\section{References}

1. Beaubien BP, Freeman AL, Turner JL, Castro CA, Armstrong WD, Waugh LG, et al: Evaluation of a lumbar intervertebral spacer with integrated screws as a stand-alone fixation device. J Spinal Disord Tech 23:351-358, 2010

2. Behrbalk E, Uri O, Parks RM, Musson R, Soh RC, Boszczyk BM: Fusion and subsidence rate of stand alone anterior lumbar interbody fusion using PEEK cage with recombinant human bone morphogenetic protein-2 . Eur Spine J 22:28692875,2013

3. Brau SA, Delamarter RB, Schiffman ML, Williams LA, Watkins RG: Vascular injury during anterior lumbar surgery. Spine J 4:409-412, 2004

4. Buttermann GR, Beaubien BP, Freeman AL, Stoll JE, Chappuis JL: Interbody device endplate engagement effects on motion segment biomechanics. Spine J 9:564-573, 2009

5. Buttermann GR, Mullin WJ: Two-level circumferential lumbar fusion comparing midline and paraspinal posterior approach: 5-year interim outcomes of a randomized, blinded, prospective study. J Spinal Disord Tech [epub ahead of print], 2013

6. Cain CM, Schleicher P, Gerlach R, Pflugmacher R, Scholz M, Kandziora F: A new stand-alone anterior lumbar interbody fusion device: biomechanical comparison with established fixation techniques. Spine (Phila Pa 1976) 30:2631-2636, 2005

7. Chiriano J, Abou-Zamzam AM Jr, Urayeneza O, Zhang WW, Cheng W: The role of the vascular surgeon in anterior retroperitoneal spine exposure: preservation of open surgical training. J Vasc Surg 50:148-151, 2009

8. Choi JY, Sung KH: Subsidence after anterior lumbar interbody fusion using paired stand-alone rectangular cages. Eur Spine J 15:16-22, 2006

9. Fleischer GD, Kim YJ, Ferrara LA, Freeman AL, BoachieAdjei O: Biomechanical analysis of sacral screw strain and range of motion in long posterior spinal fixation constructs: effects of lumbosacral fixation strategies in reducing sacral screw strains. Spine (Phila Pa 1976) 37:E163-E169, 2012

10. Freeman AL, Fahim MS, Bechtold JE: Validation of an improved method to calculate the orientation and magnitude of pedicle screw bending moments. J Biomech Eng 134:104502, 2012

11. Hsieh PC, Koski TR, O’Shaughnessy BA, Sugrue P, Salehi S, Ondra S, et al: Anterior lumbar interbody fusion in comparison with transforaminal lumbar interbody fusion: implications for the restoration of foraminal height, local disc angle, lumbar lordosis, and sagittal balance. J Neurosurg Spine 7:379-386, 2007

12. Kawaguchi Y, Matsui H, Tsuji H: Back muscle injury after posterior lumbar spine surgery. Part 1: Histologic and histochemical analyses in rats. Spine (Phila Pa 1976) 19:25902597, 1994

13. Kawaguchi Y, Matsui H, Tsuji H: Back muscle injury after posterior lumbar spine surgery. A histologic and enzymatic analysis. Spine (Phila Pa 1976) 21:941-944, 1996

14. Kim KT, Lee SH, Suk KS, Bae SC: The quantitative analysis of tissue injury markers after mini-open lumbar fusion. Spine (Phila Pa 1976) 31:712-716, 2006

15. Krishna M, Pollock RD, Bhatia C: Incidence, etiology, classification, and management of neuralgia after posterior lumbar interbody fusion surgery in 226 patients. Spine J 8:374-379, 2008

16. Lowe TG, Hashim S, Wilson LA, O’Brien MF, Smith DA,
Diekmann MJ, et al: A biomechanical study of regional endplate strength and cage morphology as it relates to structural interbody support. Spine (Phila Pa 1976) 29:2389-2394, 2004

17. Madan SS, Harley JM, Boeree NR: Anterior lumbar interbody fusion: does stable anterior fixation matter? Eur Spine J 12:386-392, 2003

18. Oxland TR, Grant JP, Dvorak MF, Fisher CG: Effects of endplate removal on the structural properties of the lower lumbar vertebral bodies. Spine (Phila Pa 1976) 28:771-777, 2003

19. Rantanen J, Hurme M, Falck B, Alaranta H, Nykvist F, Lehto $\mathrm{M}$, et al: The lumbar multifidus muscle five years after surgery for a lumbar intervertebral disc herniation. Spine (Phila Pa 1976) 18:568-574, 1993

20. Schimmel JJ, Poeschmann MS, Horsting PP, Schönfeld DH, van Limbeek J, Pavlov PW: PEEK cages in lumbar fusion: mid-term clinical outcome and radiological fusion. J Spinal Disord Tech [epub ahead of print], 2012

21. See DH, Kraft GH: Electromyography in paraspinal muscles following surgery for root compression. Arch Phys Med Rehabil 56:80-83, 1975

22. Sihvonen T, Herno A, Paljärvi L, Airaksinen O, Partanen $\mathrm{J}$, Tapaninaho A: Local denervation atrophy of paraspinal muscles in postoperative failed back syndrome. Spine (Phila Pa 1976) 18:575-581, 1993

23. Subach BR, Copay AG, Martin MM, Schuler TC: Anterior lumbar interbody implants: importance of the interdevice distance. Adv Orthop 2011:176497, 2011

24. Taylor H, McGregor AH, Medhi-Zadeh S, Richards S, Kahn $\mathrm{N}$, Zadeh JA, et al: The impact of self-retaining retractors on the paraspinal muscles during posterior spinal surgery. Spine (Phila Pa 1976) 27:2758-2762, 2002

25. Wheeler DJ, Freeman AL, Ellingson AM, Nuckley DJ, Buckley JM, Scheer JK, et al: Inter-laboratory variability in in vitro spinal segment flexibility testing. J Biomech 44:23832387, 2011

26. Wood KB, Devine J, Fischer D, Dettori JR, Janssen M: Vascular injury in elective anterior lumbosacral surgery. Spine (Phila Pa 1976) 35 (9 Suppl):S66-S75, 2010

\section{Disclosure}

Drs. Buttermann and Malcolm received industry funding for device implantation from LDR Spine USA. Institutional funding was received from LDR Spine to conduct this study. Dr. Buttermann has served as a consultant to Lifespine and Dr. Malcolm as a consultant to LDR Spine.

\section{Author Contributions}

Conception and design: Freeman, Camisa, Buttermann. Acquisition of data: Freeman, Camisa. Analysis and interpretation of data: all authors. Drafting the article: all authors. Critically revising the article: Freeman, Buttermann. Reviewed submitted version of manuscript: all authors. Approved the final version of the manuscript on behalf of all authors: Freeman. Statistical analysis: Buttermann. Study supervision: Freeman, Camisa.

\section{Correspondence}

Andrew L. Freeman, Excelen Center for Bone and Joint Research, 700 10th Ave. S, Minneapolis, MN 55415. email: andylfreeman@gmail.com. 